\title{
Knowledge Level of Pre- and Post Menopausal Women on Osteoporosis: A Cross-Sectional Study.
}

\author{
Dr. Fatima D'Silva ${ }^{1}$, Cleeta Anline Pinto ${ }^{2}$ \\ ${ }^{I}$ (Principal, Nitte Usha Institute of Nursing Sciences Nitte University, Mangalore) \\ ${ }^{2}$ (Assistant Professor, Nitte Usha Institute of Nursing Sciences Nitte University, Mangalore)
}

\begin{abstract}
:
Aim: To assess the knowledge of pre- and post menopausal women on osteoporosis.

Background: Osteoporosis is a global public health problem currently affecting more than 200 million people worldwide. It is considered to be one of the most prevalent and costly health problems in India posing an economic burden on our country. The National osteoporosis foundation has revealed that one out of two women and one out of eight males in India over the age of 50 years suffer from osteoporosis, making India one of the largest affected countries in the world.

Design: Cross sectional Design.

Methods: The study was conducted in a tertiary hospital at Mangalore in the year 2015. Fifty premenopausal women and fifty post menopausal women were selected using purposive sampling. Baseline data was collected and the knowledge was assessed using the knowledge questionnaire respectively developed by the researcher.

Results: Both premenopausal 76\% and postmenopausal 70\% women demonstrated average knowledge of osteoporosis based on their awareness questionnaire score. Comparison of the knowledge level in pre and post menopausal women showed the mean knowledge score of pre menopausal women is $11.37 \pm 3.26 \mathrm{SD}$ and mean

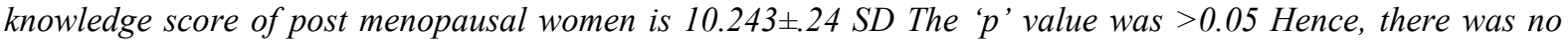
difference in the knowledge level between the pre and post menopausal women.

Conclusions: Although half of the pre- and postmenopausal women reported having some awareness of OP, their level of knowledge was average, particularly with regard to the concept, risk factors associated, treatment with the condition and its complications. Having information or creating awareness regarding the risks of OP, screening for $O P$ and a better understanding of the diet during the post menopausal period of those at risk are important, as both may play a major role in influencing an individual's OP-preventing behaviours.
\end{abstract}

Keywords: Osteoporosis, pre and post menopausal, knowledge, women

\section{Introduction}

Osteoporosis is considered to be one of the most prevalent health problems in India posing an economic burden on the country. According to a startling new survey the arthritis foundation says by 2050 , half of the world's fractures will occur in India. The World Health Organization also reports that osteoporosis is second only to cardiovascular disease as a global health care problem and medical studies show a 50 year old woman has a similar life time risk of dying from hip fracture as from breast cancer ${ }^{[1]}$. A study conducted on incidence of osteoporosis states that osteoporosis constitutes a major health problem in the western world and the incidence of fractures due to osteoporosis is increasing. The study concludes that prevention is of great importance and suggested that physical activity, combined with adequate calcium intake and hormone level is necessary for the formation and maintenance of bone tissue ${ }^{[2]}$. Although more commonly seen in women, the burden of osteoporosis in men remains under diagnosed and underreported. ${ }^{[3]} \mathrm{A}$ study was conducted on the incidence of osteoporosis over 50 years of age suggested that men account for $1 / 3$ of the 1.7 million hip fractures worldwide with a higher mortality rate than women. Osteoporosis results in longer hospital stays than several common diseases of elderly including myocardial infarction and diabetes mellitus. Osteoporosis is a major public health problem many studies have cited the incidence of vertebral or hip fractures. ${ }^{[4]}$ Osteoporosis is a condition that can be prevented and treated if diagnosed early and accurately. Unfortunately, it is often undiagnosed until a fracture occurs. Therefore, the number of people who are screened for this disease must be increased. According to the National Osteoporosis Foundation, increasing awareness is the key to prevention and early detection of osteoporosis. Unfortunately, many individuals are either unaware of their risk of developing osteoporosis, uninformed of preventive behaviors or have failed to engage in preventive behaviors as they view osteoporosis as a distant threat ${ }^{[5]}$. Perceiving osteoporosis as a major health problem among the menopausal women with adequate support of reviews the investigator problem among the menopausal women felt the need to identify the risk for osteoporosis and to determine the knowledge on osteoporosis so that an information booklet can be prepared to create awareness. 


\section{Aims}

To assess the knowledge of pre- and post menopausal women on osteoporosis.

\subsection{Design and Settings}

\section{Methods And Materials}

A descriptive design was carried in a 1200 bedded tertiary care teaching hospital to identify the risk of osteoporosis among the pre and post menopausal women and to assess their awareness on its risk factors, prevention and treatment. Written permission was obtained from the participants after proper explanation about the purpose and usefulness of the study. Confidentiality was assured to the participants.

\subsection{Participants}

Fifty pre menopausal women between the age of 25-45 years and fifty post menopausal women between the ages of 46-65 years were selected using purposive sampling technique. The sample sizes were not calculated based on power analysis it was based on the availability of the samples for the study for a period of time. The inclusion criteria were Post menopausal women aged more than 45 years and less than 65 years, Premenopausal women above 25 years and below 45 years, those willing to participate exclusion criteria were Women with existing osteoporosis, Pregnant women, Women with fracture.

\subsection{Ethical considerations}

The study was approved by the institutional ethical committee. Written permission was obtained from the medical superintendent of the concerned hospital and informed consent was also obtained from the participants after proper explanation about the purpose and usefulness of the study.

\section{Data Collection}

The pilot study was conducted from $1^{\text {st }}$ September to $31^{\text {st }}$ October 2014. The period of data collection was between November 2014 - September 2015, data were collected using an osteoporosis risk assessment questionnaire consisting of 14 questions pertaining to the risk factors leading to osteoporosis those women at moderate to high risk were assessed for knowledge using a questionnaire which consisted of 25 questions and the baseline data was collected using the demographic proforma.

\subsection{Data Analysis}

SPSS version XVI was used to analyse the data. The demographic variables and the knowledge level were compared between the pre and post menopausal women and were analysed using the independent $t$ test. To ensure the content validity, the tools along with the problem statements, hypothesis and criteria checklist were submitted to five experts from the flied of nursing and also doctors. The final data were translated by verbatim from English to Kannada by language experts.

\subsection{Validity and Reliability}

To ensure the content validity, the tools along with the problem statements, hypothesis and criteria checklist were submitted to five experts from the flied of nursing and also doctors. The final data were translated by verbatim from English to Kannada by language experts. Cronbach's alpha method was used to check the reliability of the knowledge questionnaire was 0.71 .

\section{Assessment of level of knowledge}

\section{RESULTS}

In order to find out the existing knowledge of Osteoporosis a three point scale was used and the scoring was done as follows 0-8 poor knowledge, 9-17 average knowledge, 18-25 good knowledge.

Table 1: Distribution of knowledge scores of Pre and Post menopausal women

\begin{tabular}{|l|l|l|l|l|l|}
\hline \multirow{2}{*}{ LEVEL OF KNOWLEDGE } & \multirow{2}{*}{ SCORE } & \multicolumn{2}{|l|}{ PRE-MENOPAUA } & \multicolumn{2}{l|}{ POST-MENOPAUSAL } \\
\cline { 3 - 6 } & Frequency & Percentage (\%) & Frequency & Percentage (\%) \\
\hline Poor Knowledge & $0-8$ & 10 & 20 & 14 & 28 \\
Average Knowledge & $9-17$ & 38 & 76 & 35 & 70 \\
Good Knowledge & $18-25$ & 2 & 4 & 1 & 2 \\
\hline TOTAL & & 50 & & 50 & \\
\hline
\end{tabular}

The table depicts that majority of the pre menopausal women $38(76 \%)$ had average knowledge, 10 (20\%) had poor knowledge and $2(4 \%)$ had good knowledge when compared to post menopausal women 35 (70\%) had average knowledge, 14(28\%) had poor knowledge and 1(2\%) had good knowledge regarding risk 
Knowledge Level Of Pre- And Post Menopausal Women On Osteoporosis: A Cross-Sectional Study.

factors and prevention of osteoporosis.

Area wise analysis of Knowledge Score

Table 2: Distribution of Area wise Mean, Standard Deviation and Mean Percentage of knowledge score

\begin{tabular}{|l|l|l|l|l|l|}
\hline SI.No & Knowledge Area & $\begin{array}{l}\text { Maximum } \\
\text { possible } \\
\text { scores }\end{array}$ & Mean & Standard Deviation & $\begin{array}{l}\text { Mean } \\
\text { Percentage }\end{array}$ \\
\hline 1 & Concept of osteoporosis & 5 & 1.73 & 1.09 & $35 \%$ \\
\hline 2 & $\begin{array}{l}\text { Causes , risk factors and clinical } \\
\text { manifestation of osteoporosis }\end{array}$ & 7 & 2.60 & 1.36 & $37 \%$ \\
\hline 3 & Osteoporosis preventive factors & 9 & 4.54 & 1.67 & $50 \%$ \\
\hline 4 & Diagnosis and treatment & 4 & 1.49 & 1.06 & $37 \%$ \\
\hline Total & 25 & 10.36 & & \\
\hline
\end{tabular}

Out of 25 maximum obtainable scores, the total mean score was10.36. The highest mean percentage $(50 \%)$ was obtained in the area of "osteoporosis preventive factors" with a mean $\pm \mathrm{SD}$ 4.54 \pm 1.67 . Area-wise mean percentage in the area "Diagnosis and treatment" and "Causes, risk factors and clinical manifestation of osteoporosis" was $37 \%$ with mean \pm SD $1.49 \pm 1.06$ and $2.60 \pm 1.36$ respectively. In the area "concepts of osteoporosis" the mean percentage was $35 \%$ with mean \pm SD 1.73 $\pm 1.07$

\section{Item wise analysis of Knowledge Score}

Table 3(A): Distribution of the correct responses of the women regarding "Concept of osteoporosis"

\begin{tabular}{|l|l|l|l|l|l|}
\hline SL:NO: & Items & \multicolumn{2}{l|}{ Pre menopausal } & \multicolumn{2}{l|}{ Post menopausal } \\
\cline { 3 - 6 } & & f & \% & f & \% \\
\hline 1. & Osteoporosis means porosity of the bone & 6 & 12 & 6 & 12 \\
\hline 2. & Osteoporosis of the bone commonly leads to fracture & 33 & 54 & 21 & 42 \\
\hline 3. & Body part commonly affected in osteoporosis is spine and hip & 17 & 34 & 24 & 48 \\
\hline 4. & $3-9 \%$ of bone loss occurs after menopause & 17 & 34 & 19 & 38 \\
\hline 5. & $\begin{array}{l}\text { Osteoporosis is called silent thief because it causes no } \\
\text { symptoms }\end{array}$ & 15 & 30 & 15 \\
\hline
\end{tabular}

The findings of the study revealed that majority of the premenopausal women $33(54 \%)$ knew that "Osteoporosis of the bone commonly leads to fracture, whereas the post menopausal women $24(48 \%)$ responded correctly to "Body part commonly affected in osteoporosis is spine and hip". Only 6(12\%) of the women knew that "Osteoporosis refers to porosity of the bone",

Table 3(b): Distribution of the correct responses of the women regarding "identification of risk factors"

\begin{tabular}{|c|c|c|c|c|c|}
\hline \multirow[b]{2}{*}{ SL:NO: } & \multirow[t]{2}{*}{ Items } & \multicolumn{2}{|c|}{ Pre menopausal } & \multicolumn{2}{|c|}{ Post menopausal } \\
\hline & & $\mathbf{f}$ & $\%$ & f & $\%$ \\
\hline 6 & Vitamin D deficiency leads to osteoporosis & 22 & 44 & 19 & 38 \\
\hline 7 & Deficiency of hormone estrogen leads to osteoporosis & 19 & 38 & 8 & 16 \\
\hline 9 & Osteoporosis is common among individual with thin frame & 5 & 10 & 4 & 8 \\
\hline 10 & Common cause of osteoporosis in women is menopause & 23 & 46 & 25 & 50 \\
\hline 11 & Controllable risk factor of osteoporosis is exercise & 32 & 64 & 34 & 68 \\
\hline
\end{tabular}

The highest percentage $35(70 \%)$ of the pre menopausal were aware that "the Common site of facture include all except fracture of skull \& 24(47\%) of them knew that "Menopause increases osteoporosis because production of estrogen by body is decreased", whereas the post menopausal women 34(68\%) were aware that "Controllable risk factor of osteoporosis is exercise." The least percentage $5(10 \%) \& 4(8 \%)$ of the pre and post menopausal women respectively responded correctly to the item that is "Osteoporosis is common among individual with thin frame". 
Knowledge Level Of Pre-And Post Menopausal Women On Osteoporosis: A Cross-Sectional Study.

Table 3(c): Distribution of the correct responses of the women regarding Prevention of osteoporosis

\begin{tabular}{|l|l|l|l|l|l|}
\hline \multirow{2}{*}{$\begin{array}{l}\text { SL:N } \\
\text { O: }\end{array}$} & Items & Pre menopausal & \multicolumn{2}{l|}{ Post menopausal } \\
\cline { 2 - 5 } & & $\mathbf{f}$ & $\mathbf{f}$ & f \\
\hline 22. & $\begin{array}{l}\text { Hormone used for the alleviation of symptoms following menopause } \\
\text { is estrogen }\end{array}$ & 15 & 30 & 11 & 22 \\
\hline 23. & Diagnostic measure to rule out osteoporosis is bone mineral density & 13 & 26 & 12 & 24 \\
\hline 24. & $\begin{array}{l}\text { Function of vitamin D in relation to the bones is it helps in } \\
\text { absorption of calcium }\end{array}$ & 46 & 21 & 42 \\
\hline 25. & $\begin{array}{l}\text { Treatment for osteoporosis are calcium supplements , vitamin D and } \\
\text { exercise }\end{array}$ & 23 & 46 & 31 & 62 \\
\hline
\end{tabular}

Majority of the premenopausal and post menopausal women 44(88\%) and 39(78\%) respectively were aware that "Essential mineral needed to maintain healthy bone structure is calcium". More or less $38(76 \%) \&$ $34(68 \%)$ of the pre menopausal women and $26(52 \%) \& 33(66 \%)$ of the post menopausal women knew "food item rich in calcium is milk \& Best exercise in maintaining strong bone is walking respectively. Only 11(22\%) $\& 9(18 \%)$ of the premenopausal and post menopausal women respectively responded correctly to the item "Recommended daily dietary calcium intake for adult is $300-400 \mathrm{mg} / \mathrm{day}$ ".

Table 3(d): Distribution of the correct responses of the women regarding diagnosis and treatment of osteoporosis

\begin{tabular}{|c|c|c|c|c|c|}
\hline \multirow[t]{2}{*}{ SL:NO } & \multirow[t]{2}{*}{ Items } & \multicolumn{2}{|c|}{ Pre menopausal } & \multicolumn{2}{|c|}{ Post menopausal } \\
\hline & & $\mathbf{f}$ & $\%$ & $\mathbf{f}$ & $\%$ \\
\hline 13 & Dietary source of vitamin D include egg yolk & 19 & 38 & 20 & 40 \\
\hline 14. & $\begin{array}{l}\text { Essential mineral needed to maintain healthy bone structure is } \\
\text { calcium }\end{array}$ & 44 & 88 & 39 & 78 \\
\hline 15. & $\begin{array}{l}\text { Recommended daily dietary calcium intake for adult is 300- } \\
400 \mathrm{mg} / \text { day }\end{array}$ & 11 & 22 & 9 & 18 \\
\hline 16. & Free source of vitamin D sun exposure & 31 & 62 & 25 & 50 \\
\hline 18. & $\begin{array}{l}\text { Lifestyle change to prevent osteoporosis are exercise and balanced } \\
\text { diet }\end{array}$ & 26 & 52 & 20 & 40 \\
\hline 19. & Best exercise in maintaining strong bone is walking & 34 & 68 & 33 & 66 \\
\hline 20. & Cheapest and richest source of Calcium ragi & 20 & 40 & 11 & 22 \\
\hline 21. & Recommended daily dietary requirement of vitamin D 400-600 IU & 23 & 46 & 25 & 50 \\
\hline
\end{tabular}

The highest percentage $23(46 \%)$ of the pre menopausal and $21(42 \%)$ and $31(62 \%)$ of the post menopausal women were aware that "Function of vitamin D in relation to the bones is it helps in absorption of calcium and Treatment for osteoporosis are calcium supplements vitamin D and exercise. The least percentage $13(26 \%)$ of the pre menopausal women responded correctly to the item that is "Diagnostic measure to rule out osteoporosis is bone mineral density" and $11(22 \%)$ of the post menopausal women responded correctly to the item that is "Hormone used for the alleviation of symptoms following menopause is estrogen."

Table 4: Comparison of the knowledge level in pre and post menopausal women

\begin{tabular}{|l|l|l|l|l|l|l|}
\hline Group & Mean & S.D & Mean difference & df & t Value & P value \\
\cline { 1 - 3 } Pre menopausal & 10.24 & 3.24 & & & & \\
\cline { 1 - 5 } Post menopausal & 11.37 & 3.26 & 1.120 & 98 & 1.723 & 0.08 \\
\hline
\end{tabular}

The mean knowledge score of pre menopausal women is 10.24 and mean knowledge score of post menopausal women is 11.37 and the mean difference is 1.120 . The standard deviation of knowledge score of pre menopausal women is 3.24 and for the post menopausal are 3.26. The 'p' value was $>0.05$ which indicated no significance The calculated ' $\mathrm{t}$ ' value using independent $\mathrm{t}$-test, $\mathrm{t}_{\mathrm{cal}}$ was 1.723 , which was less than the table value $\mathrm{t}_{\mathrm{tab}}(98)=1.984$ at 0.05 level of significance. Hence, there is a no difference in the knowledge level between the pre and post menopausal women.

\section{Discussions}

- Our study evaluated to have an overall average knowledge of osteoporosis among pre and post menopausal women, as well as their knowledge on Concept of osteoporosis, Causes, risk factors and clinical manifestation, Osteoporosis preventive factors, diagnosis and treatment of osteoporosis. The results of our study, which are consistent with those of other reports, indicate that several aspects of patients' knowledge and lifestyle could be improved.

- The results of the current study among the pre menopausal women 38 (76\%) had average knowledge, 10 
Knowledge Level Of Pre-And Post Menopausal Women On Osteoporosis: A Cross-Sectional Study.

(20\%) had poor knowledge and 2(4\%) had good knowledge when compared to post menopausal women 35 $(70 \%)$ had average knowledge, $14(28 \%)$ had poor knowledge and $1(2 \%)$ had good knowledge regarding risk factors and prevention of osteoporosis. Out of 25 maximum obtainable scores, the total mean score was 10.36. The highest mean percentage (50\%) was obtained in the area of "osteoporosis preventive factors" with a mean \pm SD $4.54 \pm 1.67$. in the area "Diagnosis and treatment" and "Causes, risk factors and clinical manifestation of osteoporosis" was $37 \%$ with mean \pm SD $1.49 \pm 1.06$ and $2.60 \pm 1.36$ respectively. In the area "concepts of osteoporosis" the mean percentage was $35 \%$ with mean \pm SD $1.73 \pm 1.07$. In agreement to this a study conducted on an assessment of patients' knowledge of osteoporosis in Qatar: a pilot study found irrespective of gender, $31.2 \%$ of participants had very good knowledge of osteoporosis, providing correct answers to more than $85 \%$ of the questions. most participants were able to identify several osteoporosis risk factors (smoking $63.4 \%$, low dairy products consumption $96.7 \%$, low calcium intake $96.7 \%$ ). on the other hand, fewer participants were able to identify other factors, such as the fact that thin women are at greater risk than overweight women $(17.4 \%)^{[10]}$.

- In another study, with regard to knowledge, an exploratory cross-sectional study, was conducted to assess osteoporosis knowledge showed similar findings, A convenience sample $(n=320)$ comprising of three groups aged 25-35 years, 36-45 years, and over 45 years was taken. The knowledge on osteoporosis in younger women was very poor compared to relatively older females. However, women belonging to higher socioeconomic status and better education had slightly more knowledge about osteoporosis compared to those with a low education level, regardless of age. The majority of women had modest knowledge on osteoporosis. Younger women were at increased risk for low bone mass and premature osteoporosis ${ }^{[6]}$.

- Majority of the pre menopausal women $16(32 \%)$ were in the age group of $45-50$ years, $14(28 \%)$ were in the age group of 56-60, 11(22\%) were in the age group of 61-65 years and $9(18 \%)$ in the age group of 5155 years. A similar study conducted to evaluate the osteoporosis knowledge and self-efficacy of female orthopaedic patients showed the mean age of the patients was $59.6 \pm 12 \cdot 9$ years ${ }^{[7]}$

- Majority of the post menopausal $24(48 \%)$ were illiterate, $16(32 \%)$ with primary education $2(4 \%)$ with higher primary $5(10 \%)$ graduates and $3(6 \%)$ in other category. More or less similar findings were seen in the other studies conducted to assess educational level and osteoporosis risk in postmenopausal Moroccan

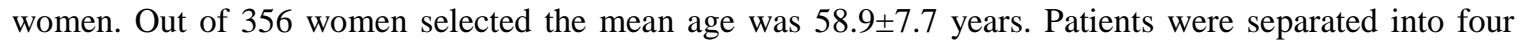
groups according to school educational level; group 1, no education ( $\mathrm{n}=98$ patients); group 2, elementary level ( $\mathrm{n}=57$ patients); group 3, secondary level ( $\mathrm{n}=138$ patients) and group 4 , university level ( $\mathrm{n}=66$ patients) ${ }^{[8]}$.

- The current study showed that premenopausal women 27(54\%) and postmenopausal women 31(62\%) had information on osteoporosis through mass media, This is in agreement with the study by Al Attia et al., which identified magazines, newspapers, and television as the major source of information among patients.

- A study conducted at Malaysia also showed similar finding with the above study, 55.7\% obtained information about Osteoporosis from newspapers and $46.4 \%$ from magazines. In this self-selected population, women, the better educated, and those earning higher incomes were more aware of Osteoporosis. $^{[9]}$

- Thus, we recommend that media outlets should be used to deliver disease specific information such as healthy lifestyle advertisements on television talks on radio, distribution of pamphlets, have shown such to be effective.

- One limitation of the study is that it did not investigate whether patients applied their knowledge to implement changes in lifestyle or dietary habits. Another limitation is the fact that study participants were not diagnosed with osteoporosis but were the post menopausal women who were at risk of developing osteoporosis. A third limitation is related to gender: even though osteoporosis is seen in men only females were enrolled in the study (osteoporosis being more common among women). In a large study $(\mathrm{n}=1514)$ of the Norwegian population, Magnus et al., found that women knew significantly more about osteoporosis than did men $(p<0.001)$. Finally, a larger sample size with adequate statistical power that is representative of the overall population is needed to generalize the findings described above

\section{Conclusion}

The results of this study showed post menopausal women were in the age group of 45- 50 years. Television and radio should be targeted in efforts to raise awareness and provide health education. Future research should examine perceptions in a larger sample of patients, as well as in the general population. This should aid in building and directing future modalities for the prevention and treatment of osteoporosis. The physicians and healthcare providers should make more effort to teach and inform patients about preventing, treating, and living with osteoporosis. Community members would be motivated by health personnel in order to mobilize the community resources for health care. Facilities like regular health check-up, screening for risk factors and follow up services should be made available to the community people. Finally an awareness 
Knowledge Level Of Pre-And Post Menopausal Women On Osteoporosis: A Cross-Sectional Study.

program about importance of prevention of osteoporosis can be organized for the general public.

\section{References}

[1]. Ref Facts and statistics/international osteoporosis foundation IOF (cited on 1/27/2014). Available on www.iofbonehealth.org/factsand-statistics.

[2]. K. AulinPiehl, H Brahm. Osteoporosis is prevented by physical activity, calcium and hormone supplementation. Lakart idningen. 1999 Jan; 96(3): 210-12 http:/ /www.nof.org/men/index.htm

[3]. Anderson Sibyl. The incidence of osteoporosis in African American Men over 50 year's age. $2^{\text {nd }}$ year research elective resident's journal. 1997 - 1998; vol II: 119.

[4]. $\mathrm{P}$ Mukkolath effectiveness of a $\quad$ self-instructional module on Osteoporosis 14.139.159.4:8080/jspui/bitstream/123456789/.../1/CDNNM SN00003.

[5]. Riaz M, Abid N, Patel J, Tariq M, Khan MS, Zuberi L. Knowledge about osteoporosis among healthy women attending a tertiary care hospital. J Pak Med Assoc. 2008 Apr; 58(4):190-4.

[6]. Aylin Ozturk, Merdiye Sendir Evaluation of knowledge of osteoporosis and self-efficacy perception of female orthopaedic patients in Turkey, Journal of Nursing and Healthcare of Chronic Illness Volume 3, Issue 3, pages 319-328, September 2011.

[7]. Allali F, Rostom S, Bennani L, Abouqal R, Hajjaj- Hassouni N. Educational level and osteoporosis risk in postmenopausal Moroccan women: a classification tree analysis. Clin Rheumatol. 2010 Nov;29(11):1269-75.

[8]. Swan Sim Yeap et al. Knowledge about Osteoporosis in a Malaysian Population. Asia Pac J Public Health 2010; 22:233-241.

[9]. Samer Hammoudeh, Magdi Hassan Abdelrahman, Prem Chandra, and Mohammed Hammoudeh An assessment of patients' knowledge of osteoporosis in Qatar: A pilot study Qatar Med J. 2015; 2015(2): 13. 